\title{
An Atypical Case of Partial Displacement and Wash-out of the Mineral Trioxide Aggregate-based Sealer in Endodontic Surgery
}

\author{
${ }^{1}$ Flávia Angélica Guiotti, ${ }^{2}$ Milton Carlos Kuga, ${ }^{3}$ Miriam Graziele Magro, ${ }^{4}$ Ana Carolina Venção \\ ${ }^{5}$ Mateus Rodrigues Tonetto, ${ }^{6}$ Keren Cristina Fagundes J ordão-Basso \\ ${ }^{7}$ Matheus Coêlho Bandeca, ${ }^{8}$ Andrea Abi Rached Dantas
}

\begin{abstract}
This clinical report described an atypical case where the mineral trioxide aggregate (MTA)-based sealer added with $20 \%$ calcium hydroxyde was used for retrograde filling. The patient was subjected to endodontic surgery to remove persistent apical lesion. After the apicoetomy and apical cavity preparation using an ultrasonic device, MTA-based sealer (MTA Fillapex) added with $20 \%$ calcium hydroxide $(\mathrm{w} / \mathrm{w}$ ) was used for retrograde filling. After 48 hours, the radiographic analysis showed partial displacement and wash-out of sealer. The case was only clinically controlled and no surgery was performed. After 10 months, the postoperative control showed reduction of periapical radiolucent image and absence of symptoms, radiographic and clinical signs, presented bone periradicular repair showing partial absence of the sealer in cavity retrograde.
\end{abstract}

Keywords: $\mathrm{C}$ alcium hydroxide, $\mathrm{C}$ alcium release, Endodontics, Flow MTA, pH, Surgery.

How to cite this article: Guiotti FA, Kuga MC, Magro MG, Venção AC, Tonetto MR, J ordão-Basso KCF, Bandeca MC, Dantas AAR. An Atypical Case of Partial Displacement and Wash-out of the Mineral Trioxide Aggregate-based Sealer in Endodontic Surgery. World J Dent 2015;6(2):108-111.

\section{Source of support $\mathrm{Nil}$}

Conflict of interest: None

\section{INTRODUCTION}

Different materials are employed for the retrograde filling. ${ }^{1}$ The mineral trioxide aggregate (MTA) is the most recommended due to its satisfactory biological properties, although presents critical drawbacks regarding handling property, such as easy displacement of retrograde cavity,

$1,3,4,6 \mathrm{P}$ ostgraduate $\mathrm{S}$ tudent, ${ }^{2} \mathrm{Ass}$ ociate $\mathrm{P}$ rofessor, ${ }^{5,7,8} \mathrm{P}$ rofessor

1-4,6,8 Department of Restorative Dentistry, Araraquara Dental School, Univ Estadual Paulista, Araraquara, São Paulo, Brazil

${ }^{5}$ Department of Integrated Dental S cience, University of C uiaba Cuiaba, MT, Brazil

${ }^{7}$ Department of Postgraduate Program in Dentistry, CEUMA U niversity; Department of Integrated Dental S cience, University of Cuiaba, Cuiaba, MT, Brazil

Corresponding Author: Matheus Coêlho Bandeca, Rua J osue Montello, S/N, Bairro Renascença, São Luis, MA, Brazil, Phone: 559882223.2998, e-mail: mbandeca@ gmail.com sandy property and wash-out tendency., ${ }^{2,3}$ These properties may adversely interferes with the clinical success of the endodontic surgery. ${ }^{3,4}$

It had been proposed MTA associations with other materials in order to solve these problems, such as calcium chloride, polymers and resins. ${ }^{2,5,6}$ New materials containing calcium silicate were developed from these associations, some material are used as light cured liners for indirect pulp capping and as obturation sealer for the root canals. ${ }^{6}$

Mineral trioxide aggregate Fillapex (Angelus, Londrina, PR, Brazil) is an MTA-based sealer for the root canals obturation, but presents excessive flow and large setting time. These properties facilitate the sealer extrusion beyond the radicular apex during endodontic filling, especially in immature apex and/or apical large foramine cases. ${ }^{7,8}$

So, in order to avoid these clinical incidents and to reduce the excessive flow, $10 \%$ calcium hydroxide (in weight) has been proposed in the sealer. ${ }^{8}$ It increases the sealer consistency, favors the clinical handling without significant changes in its properties of calcium release and $\mathrm{pH}^{7,8}$

The insertion of MTA cement in the radicular apical cavity in teeth with small apices and/or prepared using ultrasonic devices is a very difficult procedure. ${ }^{3}$ However, if a larger amount of calcium hydroxide (about $20 \%$ in weight) is added to the MTA Fillapex, the sealer presents suitable consistency to endodontic surgery and good clinical applicability and is a good option for the retrograde filling, as previous pilot tests had shown.

Thus, the aim of this case report was to describe an atypical clinical situation of a upper right lateral incisor with an apical endodontic radiolucent lesion submitted to surgery with retrograde filling with MTA-based sealer (MTA Fillapex) added with $20 \%$ calcium hydroxide (w/w). The radiographic control after 48 hours showed that the sealer was partially displaced from the retrograde cavity. However, after 10 months of follow-up, the radiographic evaluation presented periradicular bone repair and almost total elimination of the displaced material.

\section{CASE REPORT}

A 35 years old female patient reported an endodontic retreatment of the upper right lateral incisor carried out 
about 1 year ago. However, the symptoms of spontaneous pain, tooth sensitivity to vertical percussion and to palpation at alveolar mucosa next to the root apex were still persistent. The patient also related accidental trauma at the same place and the endodontic treatment of other upper incisors.

The alveolar mucosa presented normal features and sensitivity to digital palpation (Fig. 1A). Radiographic evaluation showed a radiolucent image at the upper right lateral incisor region and absence of endodontic filling in the radicular apical third (Fig. 1B). The other upper incisors presented endodontically treatment properly performed (Fig. 1C).

The selected treatment was the endodontic surgery with retrograde filling. After the local antisepsis and local anesthesia using $2 \%$ mepivacaine associated with epinephrine 1:100.000 (Mepiadre; DFL, Rio de Janeiro, RJ, Brazil), a Luebke-Ochsenbein design flap was performed, the gingival margin was not involved and vertical incisions were performed in the distal face of the upper right canine and in the distal face of the upper left incisor (Fig. 2A). The divulsion was mucoperiostal using the Freer 187-2 soft-tissue elevator tip (Golgran, São Caetano do Sul, SP, Brazil) (Fig. 2B).

The buccal bone face was partially destroyed (Fig. 2C). The bone cavity extension was performed with 699 carbide bur under irrigation with saline solution, allowing the radicular apex exposure and the removal of the periradicular lesion with a Lucas 86 curette (Golgran, São Caetano do Sul, SP, Brazil). Then apicectomy was performed with the 699 bur, perpendicular to the root long axis. The retrograde
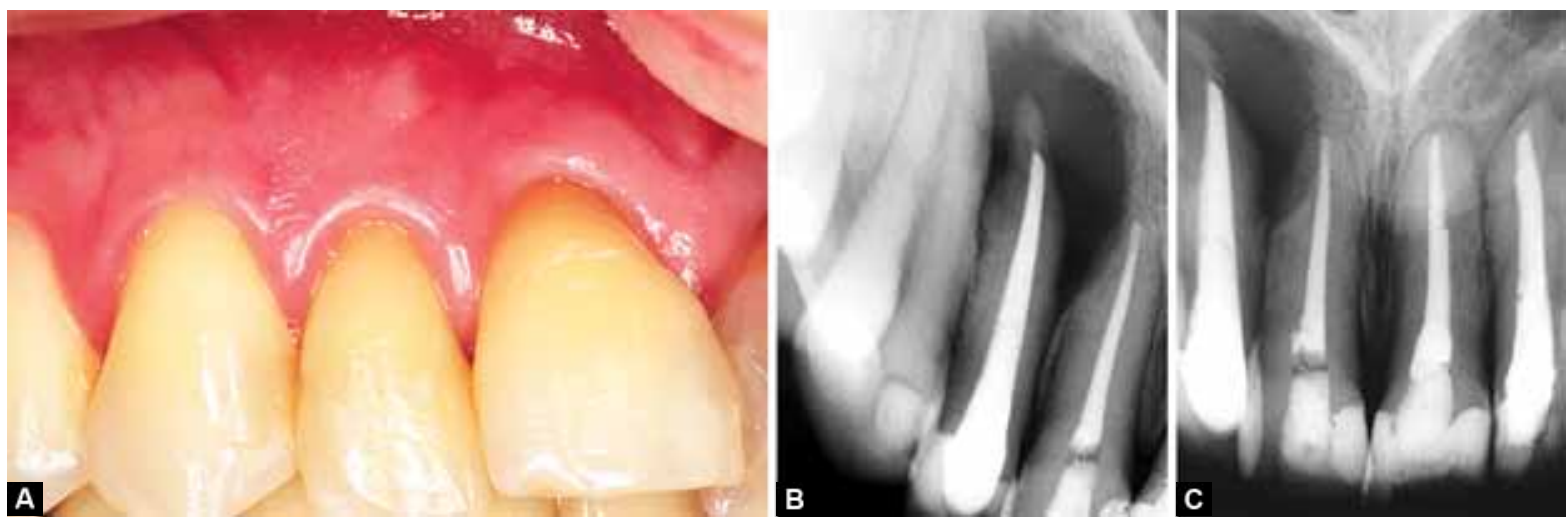

Figs 1A to C: (A) Initial clinical case, (B) periradicular lesion image and (C) endodontically-treated teeth
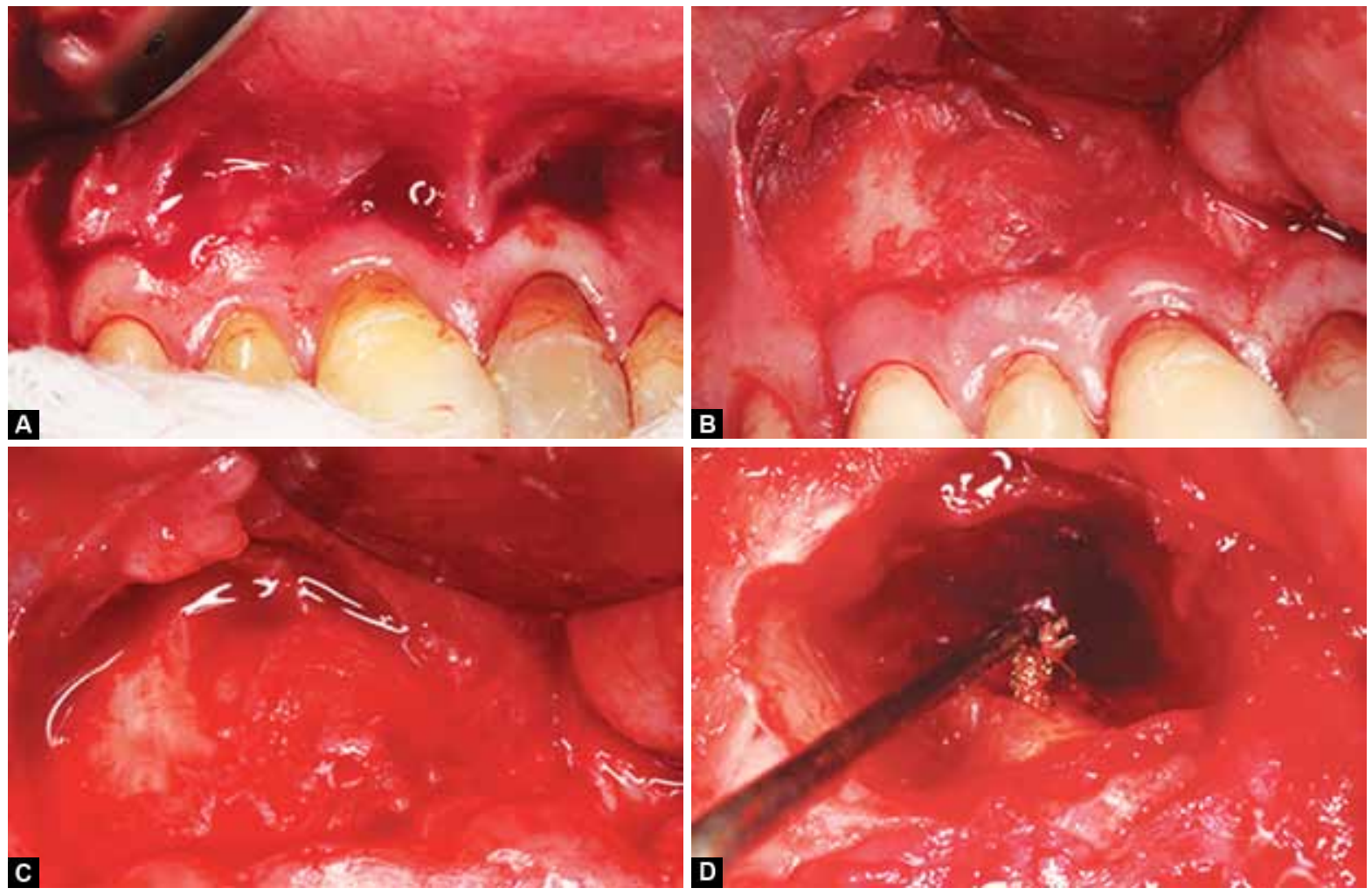

Figs 2A to D: (A) Luebke-Ochsenbein flap, (B) mucoperiostal flap,

(C) partial destruction of the osseous cortical and (D) ultrasonic tip in retrograde cavity 
cavity was prepared with P1 ultrasound tip (Helse, Santa Rosa de Viterbo, SP, Brazil), at the potency 2 of ultrasound unit (Various II; NSK, Tokyo, Japan) (Fig. 2D).

The MTA-based sealer (MTA Fillapex, Angelus, PR, Brazil) was added with $20 \%$ calcium hydroxide (Synth, Diadema, SP, Brazil) and a homogeneous compound was obtained. Following this, it was inserted into the retrograde cavity with a modified condenser. A radiographic wasimmediately taken to verify the reliability of the retrograde filling (Fig. 3A). The Luebke-Ochsenbein flap was repositioned over the alveolar bone and the suture using polyglecaprone 25 synthetic monofilament suture (Monocryl; Johnson \& Johnson, São Paulo, Brazil) was performed.

After 1 week, the suture was removed and a new radiographic was taken. In this moment, in radiographic analysis was observed the partial displacement and wash-out of the retrograde filling in the retrograde cavity (Fig. 3B). The patient presented no symptoms and without clinical signs of immediate surgical failure. After 1 month at the postoperative control, a new radiographic revealed similar image like 7 days after the surgery (Fig. 3C).

After 6 months of radiographic control, the clinical case showed that partially the sealer was reabsorbed and only fragments remained in the periradicular region. The remaining sealer in the retrograde cavity showed
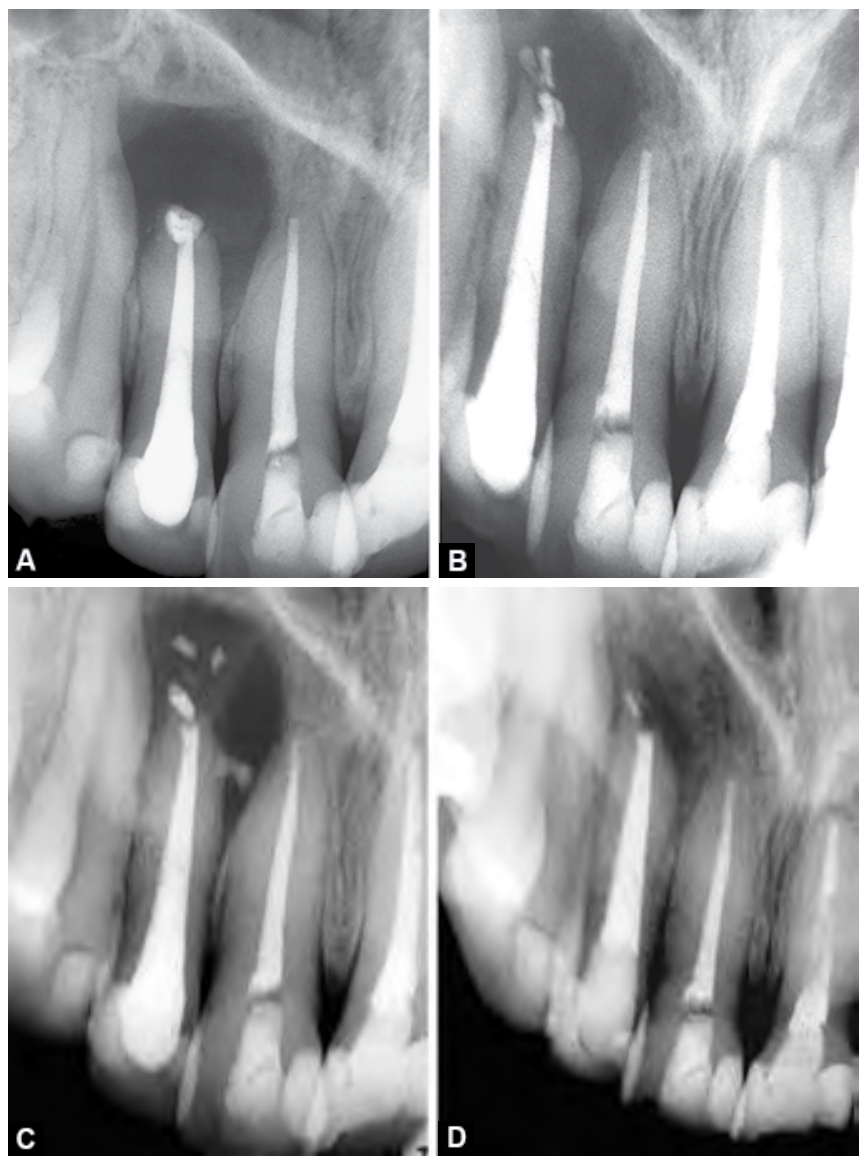

Figs 3A to D: (A) Immediate radiograph after endodontic surgery, (B) partial displacement and wash-out of the sealer after 1 week, (C) 1 month control and (D) 6 months control the same previous features (Fig. 3D). After 10 months, a new radiographic revealed practically total resorption of the displaced obturation filling and an advanced process of bone formation at the endodontic surgery region (Fig. 4A). The patient reported no more spontaneous pain or sensitivity to vertical percussion. No clinical significant changes were observed in the alveolar mucosa (Fig. 4B).

\section{DISCUSSION}

This case report described an atypical case of partial displacement and wash-out of the MTA-based sealer added with $20 \%$ of calcium hydroxide of the cavity retrograde, but with satisfactory clinical and radiographic success in the postoperative control. Mineral trioxide aggregate cement is one of the most recommend materials in problems resolution in endodontics. ${ }^{2,10}$ However, it presents some physical properties that hinders its clinical handling. 3,9,11,12

So, the chosen treatment was to add $20 \%$ calcium hydroxide in the MTA-based sealer (MTA Fillapex) to facilitate the sealer insertion into the retrograde cavity. The incorporation of $10 \%$ calcium hydroxide in the MTA Fillapex sealer reduced its flow without significant changes in $\mathrm{pH}$ and calcium release from the sealer. ${ }^{8}$ Low concentrations unfeasible this material for retrograde filling because its flow is similar to the sealer used in root canals obturation. ${ }^{7}$

The basic composition of the MTA Fillapex is silicate calcium, salicylate resin, natural resin and bismuth. ${ }^{13}$ The MTA cement contains bismuth as radiopacifier in its composition. ${ }^{2,13}$ However, this substance reduces the biological compatibility of MTA. ${ }^{14}$ Therefore, as the calcium hydroxide is the final product of MTA hydration reaction and its good biological properties are already known, it is a good substance to increase the final consistency of the MTA Fillapex. . $^{2,15}$

The Sealapex (SybronEndo, Orange, CA, USA) is an endodontic sealer containing salicylate resin and calcium in its composition and presents high solubility. ${ }^{16}$ Mineral trioxide aggregate Fillapex also presents high solubility and similar composition to Sealapex and sandy surface

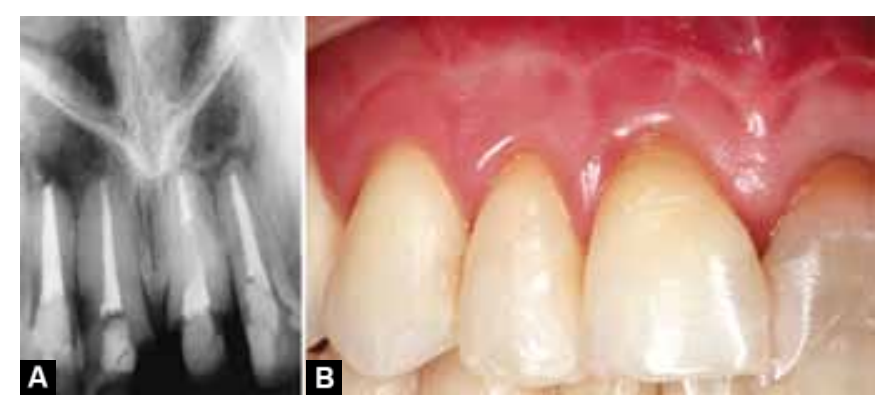

Figs 4A and B: (A) Ten months control, local bone repair and the almost complete resorption of the sealer and (B) alveolar mucosa after 10 months 
after its final set. ${ }^{17}$ In present clinical case, the incorporation of calcium hydroxide may have increased its solubility and facilitated the partial displacement of the retrograde filling of the retrograde cavity.

Despite of the partial displacement and wash-out of the retrograde filling, after 10 months of postoperative control, a decrease of the periapical radiolucent image was observed. An adequate endodontic obturation and/ or the presence of the remaining retrograde filling, about $2 \mathrm{~mm}$ from the root apex, may have contributed to the apical bone repair, once these conditions favor the repair process after endodontic surgery. ${ }^{18}$

The sealer resorption image may be associated with its fragmentation in not visible particles in the radiography image, mainly because the MTA Fillapex presents relatively low radiopacity and the incorporation of $20 \%$ calcium hydroxide could negatively interfered in this property. ${ }^{19}$ Consequently, due to its high solubility and reduced radiopacity, it was observed a progressive disappearance of the sealer in the periapical region.

Despite the MTA Fillapex presents good biological properties, the addition of $20 \%$ calcium hydroxide is questionable due to the risk of material displacement in the retrograde cavity. Further studies should be conducted to improve the handling of the MTA-based cements for endodontic surgery use.

\section{CONCLUSION}

The MTA-based sealer (MTA Fillapex) added with 20\% calcium hydroxide, when used as retrograde filling material has the risk of partial displacement and wash-out of the retrograde cavity. However, if there is partial persistence of the retrograde filling in the retrograde cavity, there is high probability of periradicular bone repair.

\section{REFERENCES}

1. Song M, Kim E. A prospective randomized controlled study of mineral trioxide aggregate and super ethoxy-benzoic acid as root-end filling materials in endodontic microsurgery. J Endod 2012 Jul;38(7):875-879.

2. Parirokh M, Torabinejad M. Mineral trioxide aggregate: a comprehensive literature review-Part I: chemical, physical, and antibacterial properties. J Endod 2010 Jan;36(1):16-27.

3. AlAnezi AZ, Zhu Q, Wang YH, Safavi KE, Jiang J. Effect of selected accelerants on setting time and biocompatibility of mineral trioxide aggregate. Oral Surg Oral Med Oral Pathol Oral Radiol Endod 2011 Jan;111(1):122-127.

4. Tang Y, Li X, Yin S. Outcomes of MTA as root-end filling in endodontic surgery: a systematic review. Quintessence Int 2010 Jul-Aug;41(7):557-566.

5. Magro MG, Venção AC, Kuga MC, Belizário LG, Tonetto $\mathrm{MR}$, Jordão-Basso $\mathrm{KC}$, et al. A new calcium silicate-based material (Biodentine) for filling radicular perforation in an endodontic-periodontal lesion: a case report. Sci J Dent 2014 Nov-Dec;1(1):42-45.

6. Malhotra N, Agarwal A, Mala K. Mineral trioxide aggregate: part 2-a review of the material aspects. Compend Contin Educ Dent 2013 Mar;34(3):e38-43.

7. Kuga MC, Duarte MA, Sant'anna-Júnior A, Keine KC, Faria G, Dantas AA, et al. Effects of calcium hydroxide addition on the physical and chemical properties of a calcium silicatebased sealer. J Appl Oral Sci 2014 Jun;22(3):180-184.

8. Keine KC, Guiotti FA, Leonardo RT, Kuga MC, Duarte $\mathrm{MAH}$, de Campos EA, et al. Influence of the addition of calcium hydroxide powder on some physical and chemical properties of the sealer MTA Fillapex. World J Dent 2012 Apr-Jun;3(2):180-183.

9. Butt N, Talwar S, Chaudhry S, Nawal RR, Yadav S, Bali A. Comparison of physical and mechanical properties of mineral trioxide aggregate and biodentine. Ind J Dent Res 2014 Nov-Dec;25(6):692-697.

10. Bali PK, Shivekshith AK, Allamaprabhu CR, Vivek HP. Calcium enriched mixture cement: a review. Int J Contemp Dent Med Rev 2014, Article ID 061214, 2014. doi: 10.15713/ins. ijcdmr.17.

11. Khandelwal A, Karthik J, Nadig RR, Jain A. 'Sealing ability of mineral trioxide aggregate and biodentine as root end filling material, using two different retro preparation techniquesan in vitro study. Int J Contemp Dent Med Rev 2015. Article ID: 150115, 2015. doi: 10.15713/ins.ijcdmr.48

12. Sonarkar S, Purba R. Bioactive materials in conservative dentistry. Int J Contemp Dent Med Rev 2015, Article ID: 340115, 2015. doi: 10.15713/ins.ijcdmr.47

13. Guiotti FA, Kuga MC, Duarte MA, Sant'Anna AJ, Faria G. Effect of calcium hydroxide dressing on push-out bond strength of endodontic sealers to root canal dentin. Braz Oral Res 2014 Jan-Feb;28(1):1-4.

14. Chen I, Karabucak B, Wang C, Wang HG, Koyama E, Kohli $\mathrm{MR}$, et al. Healing after root-end microsurgery by using mineral trioxide aggregate and a new calcium silicate-based bioceramic material as root-end filling materials in dogs. J Endod 2015 Mar;41(3):389-399.

15. Sathorn C, Parashos P, Messer H. Antibacterial efficacy of calcium hydroxide intracanal dressing: a systematic review and meta-analysis. Int Endod J 2007 Jan;40(1):2-10.

16. Ersahan S, Aydin C. Solubility and apical sealing characteristics of a new calcium silicate-based root canal sealer in comparison to calcium hydroxide-, methacrylate resin- and epoxy resin-based sealers. Acta Odontol Scand 2013 MayJul;71(3-4):857-862.

17. Borges AH, Orçati Dorileo MC, Dalla Villa R, Borba AM, Semenoff TA, Guedes OA, Estrela CR, Bandeca MC. Physicochemical properties and surfaces morphologies evaluation of MTA FillApex and AH plus. Scien World J 2014;2014:589732.

18. Holland R, Otoboni Filho JA, Bernabé PF, de Souza V, Nery MJ. Healing process of dogs' pulpless teeth after apicoectomy and root canal filling at different levels. Endod Dent Traumatol 1993 Feb;9(1):8-12.

19. Tanomaru-Filho M1, Bosso R, Viapiana R, GuerreiroTanomaru JM. Radiopacity and flow of different endodontic sealers. Acta Odontol Latinoam 2013;26(2):121-125. 